\title{
¿Políticas PARA MUJERES?: LA CONCEPCIÓN DEL TRABAJO FEMENINO EN LOS PARTIDOS POLÍTICOS DURANTE LA TRANSICIÓN A LA DEMOCRACIA. REFLEXIONES DESDE EL CASO ALMERIENSE (ALMERÍA: 1977-1983)
}

\author{
Ángeles María Segura Fernández \\ Universidad de Almería \\ anyesegura@hotmail.com
}

Recibido: 02-02-09

Aceptado: 20-02-09

\section{Resumen}

El periodo de transición a la democracia en España ha sido considerado tradicionalmente como un punto de inflexión en los vectores temáticos que marcan la agenda feminista. Los comportamientos generalmente observados en partidos políticos de diversa ideología sobre el trabajo femenino quedarán traducidos en discursos de carácter socioeconómico, que unas veces responderán a las políticas de igualdad de oportunidades reclamadas por las feministas, y otras ocasiones mostrarán residuos de la concepción tradicional del rol femenino. En este artículo se analizarán los discursos de distintos partidos políticos en distintas convocatorias electorales en el periodo apuntado anteriormente.

Palabras clave: trabajo femenino, transición a la democracia, España, situación laboral de la mujer, partidos políticos, discriminación laboral.

\footnotetext{
Abstract

The period of transition to democracy in Spain has traditionally been viewed as a turning point in the thematic vectors that set the feminist agenda. The behaviour usually
} 
seen in political parties of diverse ideologies on women's work will be translated into socio-economic speeches that sometimes respond to the equal opportunity policies claimed by feminists, and other times will remain some aspects about the traditional female role. This article analyzes the speeches of various political parties in various elections in the period mentioned above.

Key words: female work, transition to democracy, Spain, female working situation, political parties, discrimination at work.

\section{Introducción}

Situación de la mujer en el marco jurídico-laboral de los últimos años del Franquismo

La sistemática falta de autonomía de la mujer durante los cuarenta años de dictadura franquista no mermó el proceso de organización de éstas durante los primeros años de la transición. Las reivindicaciones feministas tuvieron significación especial dentro del ordenamiento de los nuevos valores democráticos, y para ello, una de las labores más urgentes fue canalizar sus demandas y la realización de sus derechos dentro del juego político. La adquisición de derechos jurídicos y políticos por parte de la mujer no ha ido acompañada de una transformación de su rol tradicional en la familia y en la sociedad en su conjunto. Estos factores, unidos a otros de carácter más general sostenidos por algunos autores (García de León, 1994; Nuño Gómez, 1999) hacen que la presencia de la mujer en el ámbito público sostuviese unos porcentajes inferiores comparados con los índices masculinos, algo que podemos observar en ámbitos como el laboral o el político.

Durante la década de los años setenta, España fue abandonando el esquema social y productivo que la había caracterizado para empezar a adoptar la "constelación de valores" propios del mundo capitalista. El crecimiento industrial y la emigración 
hacia las grandes ciudades dejaban atrás viejas formas de vida en las que la organización familiar extensa otorgaba un alto valor al trabajo doméstico y lo estimaba necesario para la supervivencia del grupo. Sin embargo, al pasar hacia una nueva sociedad donde los valores estaban regidos por las relaciones de mercado, con unos valores más acordes con una sociedad capitalista, el trabajo doméstico de la mujer va a perder progresivamente el alto estatus del que disfrutaba hasta quedar desvalorizado, e incluso va a pasar a tener una mayor dependencia con respecto al varón, quien será el encargado de soportar la carga económica del hogar.

La dura realidad económica del momento que venimos analizando, y la necesidad de alimentar proles numerosas, hizo que el trabajo de la mujer empezara a considerarse como algo natural y como ayuda / complemento al del hombre (García Nieto, 1993: 723), además de convertirse en un factor importante en la vida de las propias mujeres.

Un hecho decisivo para la incorporación de la mujer al mundo laboral, tal y como sostiene $\mathrm{M}^{\mathrm{a}}$ Ángeles Larrumbe, fue la oleada desarrollista y modernizadora del Régimen, que necesitó un incremento de la población laboral, recurriendo a la fuerza de trabajo femenina como mano de obra barata y que "no cuestionase la estructura jerárquica que otorgaba el poder al hombre” (Larrumbe, 2002: 192). Todos estos factores condicionaban y limitaban la incorporación de la mujer al mundo del trabajo extradoméstico, justo en un momento en el que el ámbito laboral europeo hacía del viejo continente “la Europa de las asalariadas” (Lagrave, 1993: 525).

Mientras que en Europa se empezaba a manifestar una etapa económica y sociológica caracterizada casi por la desaparición del trabajo independiente en su forma tradicional, así como por el debilitamiento del modelo de mujer en el hogar, en España aún persistían numerosas barreras que imposibilitaban el acceso de la mano de obra femenina al trabajo asalariado, y que hacían que España tuviera una de las tasas más bajas de empleo femenino en relación a sus vecinos europeos.

Algunos datos estadísticos pueden reflejar mejor esta situación. En 1968 España tenía un $23.8 \%$ de población activa femenina en relación con la población activa 
total, encontrándose por debajo solamente Portugal con un 20.0\%. Dos años más tarde, el conocido Informe Foessa de 1970 mostraba que más de ocho millones y medio de mujeres $(49.8 \%$ de la población activa total) se dedicaba eufemísticamente a "sus labores" y que el $80 \%$ de las mujeres con título superior permanecían inactivas (Larrumbe, 2002: 141).

Esta "no presencia" de la mujer en el ámbito laboral, aun poseyendo una titulación que la capacitara profesionalmente, sólo puede explicarse, tal y como sostiene Ma Ángeles Larrumbe (Larrumbe, 2002: 141), por razones psico-sociales que inducen al hombre a valorar positivamente la inactividad femenina o su dedicación al hogar.

Por otra parte, la situación laboral de todas aquellas mujeres trabajadoras resulta altamente reveladora. La agricultura y el sector servicios (ramas de la producción donde el trabajo suele ser más eventual o temporal) van a ser los dos sectores donde se concentre la mano de obra femenina. Por lo que respecta a la agricultura, siguiendo el estudio sociológico realizado por $\mathrm{M}^{\mathrm{a}}$ Ángeles Durán (Durán Heras, 1972: 148), hay un ligero aumento en la proporción de agricultoras respecto a trabajadoras, o lo que es lo mismo, la población activa femenina tiende a “agriculturizarse" justo en el momento en que la tónica general no es otra que el abandono progresivo del campo. Y es que como señala dicha autora, "que la agricultura se feminice parece bastante coherente con las condiciones generales de trabajo en la mujer, puesto que a igualdad en las demás condiciones, las mujeres tienden a ocupar los puestos temporales sobrantes o despreciados por los trabajadores varones, ya que el sector agrícola empezaba a convertirse en un sector poco apetecido por los trabajadores” (Durán Heras, 1972: 148). Este tipo de hechos explica la escasa presencia femenina en la continua situación de conflictividad laboral que en estos años azotaba el país; la inseguridad y la precariedad de sus contratos y salarios explican cómo en 1970, los sectores más conflictivos eran el de la construcción y el del metal, mientras que el textil, sector donde se concentraba gran cantidad de mano de obra femenina, suponía solo un $6.1 \%$ de la conflictividad total, registrándose solo 91 huelgas de las 1596 
conflictos registrados. Del mismo modo, las cifras de porcentaje de conflictividad en el sector servicios (sanidad, enseñanza y hostelería) son también insignificantes.

Tampoco podemos olvidar que esta vida laboral femenina también se caracterizaba por un alto grado de movilidad (sobre todo en aquellas mujeres que trabajaban en labores del campo y la agricultura), algo que no significaba una mejora progresiva del empleo tanto en condiciones como en salario, sino que respondía a todas luces a la "esperanza" de unas mejoras salariales, así como por su brevedad.

\section{Primeros pasos: Ley de 22 de Julio de 1961 sobre derechos políticos, profesionales y de trabajo de la mujer}

A pesar de todo lo expuesto hasta ahora, no podemos olvidar que desde comienzos del segundo franquismo las élites políticas iniciaron el desmantelamiento progresivo y aparente de numerosas barreras legales al trabajo de las mujeres. Este cambio de signo de las políticas sobre el trabajo femenino tuvo su cuerpo legal en distintas disposiciones legislativas dictadas entre 1959 y 1975, siendo la más importante la Ley de 22 de Julio de 1961 sobre derechos políticos, profesionales y de trabajo de la mujer. Esta Ley de 1961 va a tener especial importancia en las sucesivas políticas laborales destinadas a las mujeres, y si bien es cierto que es difícil encontrar unanimidad de opiniones a la hora de buscar una razón a la gestación de esta ley, lo cierto es que sí podemos afirmar que ya empezaban a sonar tímidas voces desde distintos sectores sociales que reclamaban mejoras legales y laborales para las mujeres. Tal y como señala Ma del Rosario Ruiz Franco (Ruiz Franco, 1995: 247), estas primeras voces empezaron a escucharse de forma más pertinaz a partir de los primeros años de la década de 1950. Es interesante el hecho de que, según dicha autora, estas voces provengan de algunos sectores situados dentro de las coordenadas ideológicas del Régimen, ya que supone una aportación bastante valiosa para observar la posición respecto a las mujeres del momento por parte de los elementos de poder del 
organigrama franquista $^{1}$ (Di Febo, 1979: 159). Algunas investigadoras han interpretado esta medida (parcialmente) liberalizadora como un instrumento que complemente y refuerce el giro que se pretendió dar a la economía española a través de los sucesivos Planes de Estabilización iniciados en 1959, mediante los cuales España intentaba alejarse de los oscuros años de la autarquía con la apertura de sus mercados al exterior y una mayor dinamización económica. Dicha explicación económica está basada en una necesidad urgente de facilitar mano de obra mediante la liberalización del acceso de la mujer al trabajo, dado el crecimiento económico que empezó a experimentar nuestro país, con el consecuente crecimiento de la oferta y la demanda. Junto a estos motivos, no podemos olvidar que la Ley de 1961 no solo liberalizó el acceso de la mujer a determinados puestos de trabajo y sectores a los que antes se había visto vetada, sino que además "prohibió toda discriminación laboral entre hombres y mujeres" (Di Febo, 1979: 247); esta matización se hubiera omitido si las élites políticas del régimen hubieran pretendido simplemente aumentar en nivel de producción de bienes y servicios, ya que dicho objetivo se hubiese conseguido si la legislación hubiese permitido prácticas discriminatorias como la salarial, resultándole así al empresario mucho más rentable contratar mano de obra femenina.

De hecho, esta ley estuvo respaldada por las altas instancias de Sección Femenina, cuyas opiniones en torno al trabajo extradoméstico de la mujer habían venido variando durante los largos años de dictadura, pasando de la condena del trabajo remunerado y fuera del hogar familiar por parte de la mujer casada y con hijos

\footnotetext{
${ }^{1}$ Sin embargo, no fueron éstas las únicas muestras de opinión en torno a este tema, ya que hubo también otras aportaciones desde otros sectores de la sociedad. En mayo de 1951 se celebró en Madrid el I Congreso Femenino Hispanoamericano Filipino, en colaboración con el Instituto de Cultura Hispánica y respaldado por Sección Femenina. En este congreso se trataron los problemas más importantes a los que se enfrentaban las mujeres del momento, para lo que fue estructurado en cinco comisiones, de modo que se pudiese abordar en cada una de ellas los temas más importantes relacionados con la esfera pública (profesiones, trabajo, situación legal...) y privada (familia, hogar, religión...) de la mujer. Lejos de tratarse de una mera exposición de ponencias, en la primera lectura de la III Comisión - "La mujer en la política" - se apeló a la necesidad de la pronta incorporación de la mujer al ámbito público, ya que no existía "ningún impedimento físico o intelectual que justificase su exclusión", al tiempo que se reclamaba una educación más competitiva que permitiese a la mujer desempeñar una activa participación en la política.
} 
(argumentando durante los primeros años, entre otras cosas, que el cuerpo femenino no estaba hecho para sufrir el desgaste provocado por el trabajo remunerado, de modo que iba a incidir negativamente en la capacidad reproductora) y de la defensa de la diferenciación entre trabajos específicamente femeninos y empleos masculinos, a la férrea defensa de la aprobación de esta ley que venimos analizando.

\subsection{Otras medidas parcialmente aperturistas: la Comisión Nacional de Trabajo Femenino de 1971}

Con este panorama llegamos hasta la que va a ser una de las últimas leyes referentes a la situación jurídico-laboral de la mujer en los últimos años del Régimen. Se trata de la Orden de 6 de Diciembre de 1971, por la que se crea la Comisión Nacional de Trabajo Femenino del Ministerio de Trabajo. El decreto 2310/1970, de 20 de Agosto, en su disposición adicional primera, establecía que el Ministerio crearía esta Comisión con funciones de estudio, consultivas y asesoras en materia de política laboral para la mano de obra femenina, facultada además para recoger cuantas iniciativas, quejas y peticiones en general se formulasen por personas e instituciones para la aplicación, interpretación y desarrollo de la normativa legal vigente en esos momentos.

Desde el momento de su creación, esta comisión estuvo formada por cinco ponencias, que se resumían en "Situación actual de la mujer en el orden laboral y propuesta de revisión", "Promoción social de la mujer", "Seguridad, higiene y bienestar social", "Servicios sociales y Seguridad Social" y "Trabajo de Hogar" (Vanaclocha, 1999: 274). Dicha comisión desarrolló su trabajo a través de mesas redondas, conferencias, informes y estudios sobre la situación profesional de la mujer revisando especialmente el ámbito rural y suburbano. Sin embargo, hay que tener en cuenta que en el momento en que se crea dicha Comisión, la realidad de la sociedad española no era otra que la que había generado la historia política hasta ese momento. Desde 1937, la Sección Femenina va a ser la única formación encargada de la formación, promoción y "desarrollo" de la mujer a través de una serie de servicios, entre los que se 
encontraban una labor de divulgación en materia sanitario-social, las granjas-escuelas y los centros agrícolas creados en 1940 y destinados a la captación de la mujer campesina y los servicios de ayuda al hogar, las cátedras ambulantes, los hogares rurales, las asistencias sociales y los talleres de juventud. Tal y como señala la autora $\mathrm{M}^{\mathrm{a}}$ del Mar Vanaclocha, (Vanaclocha, 1999: 274) esta ley de nuevo no supuso ningún gran avance, ya que lo que en realidad pretendía era crear puestos de trabajo femeninos en el sector rural, es decir, ofrecer a la mujer campesina un medio de incrementar los ingresos familiares sin tener que abandonar el hogar, ya que es un trabajo que consideraban compatible con sus obligaciones familiares. Esto a su vez implicaba potenciar un freno a la emigración rural y aumentar la proyección de una fuente de riqueza ya existente: la mano de obra femenina artesana, evitando así la desaparición de un trabajo abocado a la minoría y a la desvalorización comercial en plena era industrial, esto es, la artesanía. Al tiempo, dicha Comisión consiguió colateralmente que la mujer "sintiera la necesidad de dar soluciones a su paro, y retrasó por tanto, la reclamación de una cualificación adecuada en el terreno de la mecánica agrícola o de la especialización industrial" (Vanaclocha, 1999: 275).

Todos estos tímidos intentos de este momento, unidos a la influencia del turismo, el cine, la radio, e incluso el propio "efecto boomerang" de la emigración, van a proporcionar la aparición de un estado de opinión cada vez más consistente sobre la necesidad de realizar una serie de mejoras legales y laborales que catapultasen a la mujer a la esfera del trabajo extradoméstico, algo que no obviarán los partidos políticos democráticos de los años siguientes. 


\section{Los partidos políticos de la democracia ante el trabajo de la mujer}

\subsection{Posturas y opiniones respecto al trabajo de la mujer. Algunas consideraciones}

Siguiendo el hilo de las líneas anteriormente escritas, la transición hacia un nuevo modelo de estado democrático comienza con unas tasas de población femenina en paro mucho más joven que sus compañeros hombres. Según el Informe Foessa publicado en el año 1983 (VV.AA., 1983: 321), sólo trabajan o están dispuestas a trabajar el 26,9\% de las mujeres en edad activa. Estas tasas, según indica el informe anteriormente mencionado, están directamente relacionadas con la edad y con el estado civil de las mujeres, y no sólo con el nivel de instrucción: la tasa de actividad de las mujeres solteras son mucho más elevadas en 1983 que la tasa de mujeres no-solteras; sin embargo, se indica que las mujeres no solteras de 20 a 24 años con estudios superiores tienen tasas de actividad muy inferiores a las solteras de esta misma edad y estudios. Estos datos parecen indicar que el nivel de instrucción empezaba ya a romper los condicionantes del estado civil, ya que permitía la integración laboral plena.

Por lo que respecta a las causas de inactividad femenina, el mismo informe cita como causa del alto desempleo femenino el que "las mujeres buscan empleos acomodados a un horario especial, a una localización concreta, o de una naturaleza especifica, y por ello, resultan auto discriminadas" (VV.AA., 1983: 325), obviando que la auto discriminación podría venir impuesta por el cumplimiento de un rol esencial dentro del ámbito privado.

Unos pocos años antes de la publicación del Informe Foessa citado anteriormente, otro estudio publicado a comienzos de la década de los 70 planteaba otro aspecto fundamental para entender estas cifras relativas al desempleo femenino en este momento histórico estudiado. Dicho informe apuntaba, además de las causas demográficas, económicas y políticas, otro tipo de condicionamientos psico-sociales que se ejercen sobre las mujeres; estos condicionamientos, según afirmaba, "podían 
incluso llegar hasta a oponerse a los objetivos económicos y sociales prevalentes, haciendo más dificiles las mutaciones" (Caillavet, 1987: 113). Aborda, así, la prevalencia de los mitos sobre las realidades femeninas en cuestiones de índole laboral, entroncando con la cuestión de lo que France Caillavet denomina "sistema del honor", que corresponde a la distribución de los papeles en la familia nuclear española de la década estudiada. Así, la constelación del honor femenino apuntaba que una mujer preservaría su vergüenza al abstenerse de las acciones que les son propias a los hombres, como el trabajo exterior, al tiempo que se borra a la actividad doméstica de todas las características de un trabajo (status y remuneración económica), puesto que entra dentro del ámbito de "sus labores" (dotando a la palabra "labor" de un contenido moral, que puede remitir a la idea de vocación o deber, distinta siempre a la carga semántica de la palabra "trabajo").

Vemos, pues, que junto con la persistencia de ciertas opiniones residuales de corte tradicionalista, la cuestión del "desempleo" femenino empieza a convertirse en un problema, el problema del "paro" femenino, algo que los distintos partidos políticos incluirán dentro de sus propuestas electorales, al suponer el voto femenino algo más del $52 \%$ de los votantes en este momento estudiado.

\subsection{Los partidos políticos ante el empleo / desempleo femenino}

\subsubsection{La temática feminista en los partidos políticos: ¿electoralismo o buenas intenciones?}

La eclosión del movimiento feminista de segunda generación y la introducción de prácticas democráticas dentro del juego político tras la muerte de Franco fueron procesos paralelos, con puntos de contacto comunes, bien por el propio beneficio electoral de los bloques políticos, bien por la fuerza motriz de las reivindicaciones de los grupos feministas. 
Algunos autores (Guzmán, 2001) señalan que las políticas públicas son el resultado de los procesos sociales iniciados previamente en las bases de la ciudadanía. Es en esta esfera social donde se construyen y definen los problemas que se consideran de importancia suficiente para copar las primeras páginas de la agenda pública. La elaboración de nuevos marcos para la reinterpretación de la realidad social resulta fundamental, más aún cuando esto proceso va acompañado por el resurgimiento de nuevos actores sociales, como fueron las mujeres del movimiento feminista organizado. De ahí la importancia de considerar la discriminación hacia la mujer un problema de interés público, ya que, más que afectar a un colectivo determinado, afectaba a la mitad de la población española.

La posición social y política de la mujer española durante los años de la dictadura se consideraba predeterminada por la propia naturaleza femenina, y por ello, no era cuestionada. Sin embargo, en la medida en que el feminismo puso en tela de juicio esta concepción, los bloques políticos que se disponían a iniciar su carrera democrática hacia el poder tuvieron que revisar sus planteamientos al respecto, e incorporar la temática feminista dentro de la idiosincrasia propia de cada ideología. Especial importancia revisten las feministas de doble militancia, ya que fueron, en gran medida, las encargadas de incorporar las demandas de género a la ideología de sus respectivos partidos. El objetivo último sería siempre la implementación de las políticas de género, algo que veríamos durante los últimos años de la década de los ochenta.

\subsubsection{La cuestión el trabajo femenino en el PCE, el PSOE y otros partidos minoritarios}

Tal y como afirma Judith Astelarra (Astelarra, 2005: 129), el movimiento feminista, a través de sus feministas de doble militancia, estuvo vinculado a los dos grandes partidos de izquierda con representación parlamentaria, el PSOE (Partido Socialista Obrero Español) y el PCE (Partido Comunista de España). Ambos bloques 
serán los primeros que empiecen a introducir las demandas feministas a la agenda pública.

Tanto en estos dos partidos, como en otros que analizaremos posteriormente, la cuestión del trabajo femenino siempre aparecerá relacionada con otros dos grandes temas, como eran la familia y la necesidad de ampliar la red de cobertura social, de la que sería la mujer la gran beneficiada. El trabajo femenino nunca será abordado como un tema específico, sino como una particularidad más del conglomerado de situaciones que provocan la discriminación de la mujer.

El PCE, por su parte, centró el debate de su primer congreso en la legalidad de 1977 sobre el movimiento obrero y su papel de transformación de la sociedad. Recordemos que, hasta este momento, las tesis comunistas subordinaban la liberación de la mujer a la liberación del movimiento obrero. A lo largo de estos años, las comisiones de la mujer creadas dentro de las agrupaciones del partido, organizarían charlas sobre temas dominantes de la realidad feminista del momento, como el aborto, los anticonceptivos, la familia, o la explotación femenina, dentro del proceso de mayor democratización interna del partido. El PSOE también recurrió a la creación de una comisión encargada del estudio del prisma de la discriminación femenina. La comisión Mujer y Socialismo en 1976, dependiente de la secretaría de formación del partido, sería la encargada de elaborar una labor de formación que explicara la temática del feminismo y la falta de igualdad entre los sexos. En estos dos partidos, dichas comisiones serían las encargadas de estudiar el problema relacionado con la realidad laboral discriminatoria femenina.

En las elecciones constituyentes de 1977, el PCE publicaría una guía electoral con motivo de esta consulta a urnas. Dicha guía contaría con nueve puntos fundamentales, ocupando el quinto lugar la necesidad de conseguir la completa igualdad de derecho para la mujer. Así afirmaban la necesidad de "acabar con las leyes que hacen que la mujer no sea una ciudadana de pleno derecho. Y no podría existir progreso social si no se produce una emancipación efectiva de la mujer como 

políticos durante la transición a la democracia. Reflexiones desde el caso almeriense (Almería: 1977-1983)

trabajadora y como ciudadana",2 Para los comunistas, la firma de la Carta Magna debería incluir la garantía de la completa igualdad de derechos para la mujer, que consistía en "otorgar la necesidad jurídica como el divorcio, que no sólo regule comportamientos sociales injustos, sino que eliminará la dependencia brutal a la que está sometida la mujer"”. La enseñanza obligatoria y gratuita se convertía en un reclamo, junto con la creación de guarderías y centros maternales, que "a su vez faciliten el acceso de la mujer al mundo laboral "A.

Dos años más tarde, y con motivo de las elecciones generales de 1979, el Partido Socialista Obrero Español presentaba una guía en los medios de comunicación locales donde también hacía hincapié a la discriminación de la mujer dentro de un bloque dedicado al bienestar social, alegando que "es necesario, para conseguir la incorporación de la mujer a la vida social, en plena igualdad con el otro sexo, una educación sin discriminaciones, con la superación de los hábitos y los textos que asignan a las niñas papeles secundarios; se hace igualmente necesario la creación de guarderías infantiles y laborales, que permitan trabajar a la mujer fuera de casa "5.

En esta misma consulta electoral de 1979, el bloque político denominado Coalición Democrática cumplirá la paradoja de ser un partido joven con pocas posibilidades de éxito electoral, aunque también el que desarrolle una programación feminista más explícita dentro de su programa. Los puntos fundamentales abordados desde esta perspectiva por este partido político girarían en torno a la creación de un ministerio de la familia, a la implantación de una enseñanza donde los padres puedan decidir sobre la educación laica o religiosa de sus hijos, y el acceso a una vivienda digna. Por lo que respecta al objetivo fundamental de este trabajo, la propuesta en torno a la erradicación del paro femenino giraría sobre el fomento de actividades y servicios comunitarios que procuren un empleo adecuado y sin discriminaciones para la mujer,

\footnotetext{
${ }^{2}$ La Voz de Almería, "Hoy, Partido Comunista de España", 1 junio de 1977.

${ }^{3}$ Ibíd.

${ }^{4}$ Ibíd.

${ }^{5}$ La Voz de Almería: "Programa para un gobierno socialista". 8 de Febrero de 1979. p. 7.
} 
así como la reforma de las prestaciones de la seguridad social, y la protección legal del trabajo del ama de casa, con seguridad social gratuita.

Sólo un mes más tarde, el mes de abril de 1979 serviría nuevamente para recrear estas propuestas, esta vez dentro del imaginario político propuesto para las primeras elecciones municipales democráticas. El II Congreso celebrado por el PSOE en Sevilla ese mismo año incluiría un bloque específico sobre mujer y feminismo; ahí encontraríamos las propuestas más importantes de este partido en materia feminista, dentro de cinco puntos fundamentales sobre trabajo, educación familia, sociedad y prostitución. Por lo que a la materia laboral se refiere, los socialistas empezarían a incluir especificidades de la desigualdad laboral femenina, como la necesidad de la igualdad salarial de la mujer en las faenas agrícolas, o el cumplimiento obligatorio de los convenios colectivos definidos en el ámbito agrícola, y la creación de una seguridad social para las trabajadoras del campo. El servicio doméstico será otro punto de este apartado, en el que abogarían por un contrato obligado para las trabajadoras de este servicio, que incluya pagas extraordinarias, vacaciones anuales, y cuarenta horas de trabajo semanal. La re-estructuración del horario laboral para lograr la conciliación de la vida laboral y familiar será otra demanda defendida por el PSOE, junto con la formación profesional permanente (que facilite el acceso al mundo laboral a las mujeres de cualquier edad). Nuevamente, encontraremos referencias a la creación de guarderías potenciadas por el mismo partido a nivel municipal, que cumplan la doble misión asistencial y educativa que permita el acceso de la mujer al trabajo comunitario. Por último, abogarán también por la erradicación del trabajo típicamente femenino ${ }^{6}$.

Esas líneas marcadas en este congreso socialista quedarían insertas también dentro del programa que este partido diseñaría para las elecciones generales de 1982; aquí ya encontraríamos medidas de fomento del empleo femenino a través de una campaña conjunta entre gobierno y sindicatos, que conciencie a la mujer a que se

\footnotetext{
${ }^{6}$ II Congreso del Partido Socialista Obrero Español de Andalucía. Sevilla, 7-9 diciembre de 1979. Memoria de Ponencias sobre Mujer. Pp. 87-89. Archivo del Partido Socialista Obrero Español de Almería. Sección Elecciones 1979. Legajo 1. Almería.
} 
inscriba en las oficinas de empelo y las haga constar como desempleadas. Seguirían apostando por la reducción de la jornada laboral para facilitar la conciliación con la vida familiar, así como por la creación de un estatuto que garantice los derechos laborales de las empleadas del hogar. Sin embargo, la única novedad dentro de estos puntos ya perfilados sería la incorporación de una protección de la maternidad de la mujer trabajadora, con el objetivo de evitar que el embarazo se convierta en motivo de despido.

\subsubsection{El trabajo femenino según Alianza Popular y otros partidos políticos de tipo conservado}

La identificación de la "derecha" con planteamientos contrarios al feminismo ha tenido una dilatada tradición en España, a través de la comunidad de intereses creada entre el conservadurismo y el catolicismo, propio de gran parte de la sociedad española durante la dictadura. Algunas autoras, como Antonia Ruiz Jiménez (Ruiz Jiménez, 2002: 149), sostienen que la alternativa presentada por partidos de ideología conservadora consiste en un cambio ideológico de las bases de este partido con el doble objetivo de maximización electoral, y de reiteración de un carácter más democrático (un cambio de estética con aquellos cargos provenientes del Franquismo). Los temas de acceso y participación de la mujer dentro del ámbito público han recibido poca atención en los programas electorales de AP, si bien es cierto que podemos encontrar cierto discurso oculto en las afirmaciones de sus líderes locales.

Con motivo de las elecciones constituyentes de 1977, la candidata local por Almería Ángela Cuenca Lorca mostraba una opinión respecto a la situación de la mujer basada en un "reconocimiento de las diferencias" con respecto al hombre, y en una serie de atributos que bien dejan entrever su marcada formación dentro de Sección Femenina. Los movimientos feministas van a ser descritos por esta candidata como un punto de partida o un lugar de inflexión en una sociedad y en una cultura que describe como injusta, al tiempo que va a aceptar ciertas reivindicaciones del movimiento 
organizado, aún cuando no está de acuerdo con los argumentos utilizados. Según afirmaba en la prensa local, el camino encauzado por las feministas no es el correcto, debido en gran parte a la adscripción de estas a partidos de izquierda, que podrían ideologizar el discurso ${ }^{7}$. Propone, para ello, que la conquista del ámbito laboral y político por parte del movimiento feminista pase, irremediablemente, por el reconocimiento de las diferencias entre hombres y mujeres, considerando indispensable este reconocimiento en cuanto a aspectos físicos y psíquicos, si que ello implique la desigualdad para la mujer, ni una presunción de especificidades femeninas como signo de inferioridad. Sin embargo, si el reconocimiento de estas diferencias es el principio de igualdad de oportunidades que llevará la mujer a entrar dentro del ámbito laboral, lo cierto es que esta candidata hará gala de esas diferencias para hacer a la mujer más apta por sus cualidades típicamente femeninas. Así, destacará el "ingenio" para presentar propuestas de forma más sugestiva, su "acusada sensibilidad" para detectar problemas, su "intuición" para hallar soluciones, su "perspicacia" para descubrir la verdad, su “emotividad” para arrastrar tras de sí a los que piensen como ella, su "persuasión” para lograr que los demás cambien de criterio, su "habilidad" para quedar en segundo plano, y su "tesón y perseverancia" para mantenerse firme ante la adversidad.

Otro partido que acude a las elecciones constituyentes de 1977 será Alianza Nacional 18 de Julio, de marcado carácter falangista, y que abogará por "el honor, la

\footnotetext{
${ }^{7}$ Según afirmaba esta candidata, "las estrategias reivindicativas del movimiento feminista son de autoexclusión de su realidad sociocultural, adoptando posturas radicalizadas; ello implica un esfuerzo, a partir de esta posición han de realizar otra nueva lucha para integrarse imponiendo su actitud. Como consecuencia de esta contradicción, hay un doble esfuerzo y esto origina una pérdida del mismo y una pérdida de energía, así como una desviación de contenidos, derivados de los cambios de estrategia para penetrar en algo de lo que habían sido excluidas. De este modo entiendo yo la lucha de la mujer, y su esfuerzo en orden de cambiar una realidad sociocultural que no le es favorable. Por ello ha de estar en base este deseo de reivindicar una forma de conciencia a nivel individual y como consecuencia de la cual, constituirse en fermento de evolución, en orden de cambiar los códigos culturales imperantes, de una forma natural, no en base a esquemas ideológicos tipificados, que de por si pueden originar rechazo". En La voz de Almería. "Los movimientos feministas: Entrevista con Ángela Cuenca Lorca, diputado provincial y presidente de la Comisión de Asistencia Social”. 1 de Mayo de 1977. p.6.
} 

políticos durante la transición a la democracia. Reflexiones desde el caso almeriense (Almería: 1977-1983)

disciplina social y el trabajo desinteresado a la comunidad hasta el sacrificio"» como puntos básicos de la acción de la mujer en el terreno público. Esta concepción de corte ultra conservador será ratificada por su candidata local en Almería, Josefa Ramón Zumaquera, quien animaba a todas las mujeres a seguir su ejemplo como "ama de casa, misión tan digna como cualquier trabajo honrado" ".

Como observamos, la escasa atención que los partidos políticos prestaron, en este momento histórico analizado, a la problemática específica del trabajo femenino no va a pasar desapercibida. La población femenina en edad de votar, en este momento coyuntural, suponía el 52\% del electorado, y la gran mayoría de este porcentaje parecía escorarse hacia el voto indeciso o útil ${ }^{10}$.

\section{Conclusiones - Propuesta en materia laboral: "la predicación en el desierto"}

A lo largo de las distintas consultas electorales celebradas durante el periodo tradicionalmente considerado de transición a la democracia, las dos hipótesis manejadas para abordar el rol femenino en este proceso permanecieron invariables: la presencia de la mujer es muy baja (entendiendo por presencia su candidatura o elección), y los partidos políticos normalmente se han mostrado como grandes bloques reacios a la intromisión de propuestas feministas, siempre y cuando no fuera por un bien electoral.

El baile de cifras sólo nos permite ver que en las seis consultas electorales analizadas, el número de mujeres electas es ínfimo comparado con el número de electos;

\footnotetext{
${ }^{8}$ La Voz de Almería: "Hoy Alianza Nacional 18 de Julio", 27 de mayo de 1977. p. 12.

${ }^{9}$ Ibíd.

${ }^{10}$ Así quedaba registrado en la prensa local, donde se afirmaba que "quizás debieran prestar mayor atención por parte de los estrategas de los partidos políticos hacia lo que ha dado en llamarse el voto femenino. Las mujeres, según los estudios, son una ligera mayoría, algo más del $52 \%$, y parece que el número de indecisos entre ellas es mayor". En La Voz de Almería: "En la recta final. El voto femenino y otros pormenores". 7 de Junio de 1977. p. 3. Según señala este mismo artículo, de 813 señoras consultadas, 98 dicen que no saben si votarán o no, mientras que de 825 hombres, sólo son 53 los que no se deciden. Además, afirmaba no sólo la no intención de voto, sino la indecisión de su objeto de votación.
} 
sólo en las elecciones municipales destaca algo más el número de elegidas, pero siguen comprendiendo porcentajes minúsculos comparados con sus correlativos compañeros masculinos. Ante las causas de esta desproporción, podríamos manejar diversas teorías, o incluso un análisis más exhaustivo de las propias candidaturas. Algunas autoras (Nuño Gómez, 1999; García de León, 1994) señalan como causa de este divorcio entre mujer y política el propio carácter o génesis de la actividad política. Si analizamos el sistema político a través de la perspectiva propia de las mujeres, es decir, a partir de sus propios intereses específicos, veremos que la política, tal y como estaba configurada en el momento histórico estudiado en este trabajo, permitía duramente su participación.

Tabla resumen de candidatas y electas sobre el total de las candidaturas (1977-1983)

\begin{tabular}{|c|c|c|c|c|c|}
\hline Elecciones & Candidatos Totales & Candidatas & $\boldsymbol{\%}$ & Electas & \%* \\
\hline Constituyentes 1977 & 37 & 7 & $118,90 \%$ & 1 & $14,28 \%$ \\
\hline Generales 1979 & 85 & 11 & $112,90 \%$ & 1 & $9,09 \%$ \\
\hline Municipales 1979 & 3143 & 162 & $55,15 \%$ & 20 & $12,34 \%$ \\
\hline Parl. Andalucía 81 & 99 & 17 & $117,17 \%$ & 0 & $0 \%$ \\
\hline Generales 1982 & 114 & 19 & $116,60 \%$ & 0 & $0 \%$ \\
\hline Municipales 1983 & 3322 & 214 & $66,40 \%$ & 44 & $20,56 \%$ \\
\hline
\end{tabular}

* Porcentaje de electas sobre el número total de candidatas.

*Elaboración propia según datos de BOP y prensa consultada.

Si de lo que se trataba era de instaurar una democracia (entendiendo que la democracia se basa en la participación de todos los ciudadanos en la elección de sus dirigentes y gobernantes, y en la existencia de unos derechos individuales que el sistema político y las instituciones del propio Estado deben proteger), el sistema de género vigente en el momento en que empieza la transición, un sistema que condicionaba las relaciones entre los sexos y determinaba la discriminación y subordinación de la mujer, era un sistema profundamente androcéntrico y antidemocrático, pues su base social estaba fraguada sobre la desigualdad. 
La situación de las mujeres en la política era sólo un espejo que proyectaba cómo las mujeres no disfrutaban de los principios democráticos que las élites políticas intentaban instaurar. Estas limitaciones democráticas y participativas fueron especialmente acentuadas en la arena política en lo concerniente a la situación femenina, puesto que su ausencia es mayor que en otras instancias sociales. Una mayor presencia y participación de las mujeres en el ámbito político, en un momento trascendental en la historia de España, hubiera supuesto un mayor equilibrio democrático, ya que es en el seno de la vida política donde nació la convicción de que la democracia debía progresar en la igualdad de hombres y mujeres. Esta concepción de la participación femenina requirió una nueva redefinición de la democracia, algo que no se hizo.

Siguiendo con los partidos políticos, la temática feminista en las estrategias discursivas será escasa en los programas electorales, así como en los planteamientos internos de los propios partidos. Sólo en aquellos bloques políticos donde sus militantes y candidatas habían participado en el movimiento feminista, se considerarán estos temas referentes a la mujer a gran escala. Pero de nuevo, estos partidos serán minoritarios o de escaso éxito electoral. Nos estamos refiriendo a partidos como el Frente Democrático de Izquierdas, la Organización Revolucionaria de Trabajadores, el Partido del Trabajo, o el Movimiento Comunista de Andalucía - Organización Izquierda Comunista.

Si bien en época electoral todos los partidos políticos se harán eco de los dos temas estrella, aborto y divorcio, estos pequeños partidos mencionados anteriormente considerarán además otros temas como la discriminación salarial, el reparto de tareas domésticas, la planificación familiar, las guarderías, etc. Esto no es de extrañar si bien algunas asociaciones del tipo Asociación para la Promoción de la Mujer, el Movimiento Democrático de Mujeres y la Asamblea de Mujeres de Almería, habían servido de cantera política a estos partidos, propiciando así una doble militancia que favorecerá forzosamente este debate feminista en el seno de los partidos políticos. De igual forma, se puede generalizar que los partidos tradicionalmente situados a la izquierda, - PSOE, PCE-PCA, FDI, MCA-OIC, etc. - se mostrarán a favor del divorcio y el aborto, así 
como de todas aquellas propuestas que estaban encaminadas a erradicar la situación desigual de la mujer. Por el contrario, los partidos como UCD, AP y los extremos de FN o Falange defenderán una versión de la familia tradicional basada en principios cristianos, y mostrarán un "no" rotundo al aborto y al divorcio.

Vemos así que empieza a gestarse la ruptura de la concepción tradicional del argumentario feminista como un tema sectorial (como podría ser la infancia, o la tercera edad), preparándose el giro discursivo hacia la legitimidad paritaria (si bien ésta habría de llegar muchos años después).

Según lo anteriormente descrito, y puesto que no podría ser de otra manera, la primera conclusión con respecto al objetivo de este trabajo es bien clara: las reivindicaciones del movimiento feminista en materia laboral no serán un tema monográfico dentro del seno de debate de los partidos políticos. La discriminación laboral no sería un tema con identidad propia a estudiar dentro de los programas de diversa idiosincrasia ideológica, sino que irá unido a otros grandes bloques ideológicos como la familia o los servicios sociales. Esto hace que el ítem "Mujer y Trabajo" no aparezca como un marco de referencia, sino que estará siempre sujeto a otros marcos profundos, que determinarán la posición a adoptar en este tema. Esto, a su vez, significa que la actitud política ante el trabajo femenino estará marcada por el concepto de familia dominante en cada seno político, de modo que aquellos partidos que apostaron levemente por una alternativa al modelo de familia nuclear tradicional, se mostrarán a favor de erradicar aquellas barreras sociales y legales que impiden el desarrollo de la actividad laboral femenina en igualdad de condiciones. Estos partidos serán, igualmente, los que también apostarán en un futuro próximo por la despenalización del aborto, así como por el divorcio.

Muy por el contrario, se observa que aquellos partidos donde la concepción de la familia está enmarcada dentro de la tradición católica tradicional, la actitud hacia el trabajo de la mujer fuera del ámbito doméstico nunca será negativa, sino de omisión.

Es decir, la estrategia consistiría en un cambio de estética hacia este respecto, pero sin que esto llegue a suponer un apoyo total y decidido. De hecho, estos partidos 
políticos de raigambre tradicional-conservadora, apostarán por incluir en sus listas mujeres cuya dedicación se circunscribe al ámbito doméstico, optando por la imagen de la mujer tradicional, “ángel del hogar” y ama de casa. Esto es fundamental si consideramos la construcción cultural del género a través de los modelos sociales y políticos en este momento.

Por otro lado, y siguiendo la idea de la falta de identidad del trabajo femenino como un marco profundo de referencia, lejos de abordar por completo las discriminaciones de índole social y legal que incurrían en este propósito, los partidos políticos considerarán la ampliación de la red de servicios sociales como una alternativa a la falta de proyección pública de la mujer. Los capítulos dedicados a la creación de nuevas guarderías, a la ampliación de los horarios escolares, y la creación de otras redes asistenciales a favor de la mujer trabajadora son mucho más numerosos que aquellos dedicados a la discriminación salarial, o al embarazo como motivo de despido. Además, cuando se habla de adecuar los horarios de las guarderías para "conciliar" los trabajos de las mujeres con la educación de sus hijos, se apuntaba ya a una idea que ha prevalecido durante toda la democracia hasta días muy recientes. La conciliación se entendía sólo en términos de la vida laboral y familiar, obviando por completo la vida personal de estas mujeres que empezaron a copar el sector público.

Tal y como hemos abordado en este trabajo, las mujeres no formaron parte de las élites políticas que encaminaron al país, y en concreto a la ciudad de Almería, a la democracia. En este sentido, la defensa de sus intereses y objetivos - en un momento en el que la situación de la mujer se puede calificar de discriminatoria y subordinada quedaron en manos ajenas. Por ello, podemos concluir afirmando que estas instituciones gubernamentales, y los órganos políticos que en ellas participaban, estaban configurados sobre la base de la desigualdad, con lo que se instauró desde el principio una democracia incompleta. 


\section{BIBLIOGRAFÍA}

- Astelarra, J. (2005): Veinte años de políticas de igualdad. Madrid: Cátedra.

- Astelarra, J. (1986): Las Mujeres Podemos: otra visión política. Barcelona: Icaria.

- Barrio, E. (1999): Espacios públicos en clave de sexo / género: la transición a la democracia (empresariado, educación y política) (Andalucía, 1970-1981). Granada: Comares.

- Di Febo, G. (1979): Resistencia y Movimiento de mujeres en España: 1936-1976. Barcelona: Icaria.

- García de León, M. A. (1994): Élites discriminadas: sobre el poder de las mujeres. Barcelona: Anthropos.

- Larrumbe, M. A. (2002): Una Inmensa Minoría: Influencia y feminismo en la Transición a la Democracia en España. Zaragoza: Prensas Universitarias de Zaragoza.

- Miyares, A. (20032): Democracia feminista. Madrid: Cátedra.

- Nielfa Cristóbal, G. (2003): Mujeres y hombres en la España Franquista (sociedad, economía, política y cultura). Madrid: Instituto de Investigaciones Feministas. Universidad Complutense de Madrid.

- Nuño Gómez, L. (1999): Mujeres: de lo privado a lo público. Madrid: Tecnos.

- Rivera, M. (2003): Mujeres en relación: Feminismo: 1970-2000. Barcelona: Icaria.

- Ruiz Jiménez, A. (2002): Mecanismos de cambio ideológico e introducción de políticas de género en partidos conservadores: el caso de AP - PP en España en perspectiva comparada. Madrid: Instituto Juan March de Estudios e Investigaciones.

- Santesmases, M. J. (2000): Mujeres Científicas en España (1940-1970). Profesionalización y modernización social. Madrid: Ministerio de Trabajo y Asuntos Sociales. Instituto de la Mujer.

- Sullerot, E. (1970): Historia y sociología el trabajo femenino. Barcelona: Península.

- VV.AA. (1983): Informe Sociológico sobre el cambio social en España. 1975-1983. IV Informe Foessa. Volumen II. Madrid: Fundación Foessa. 

políticos durante la transición a la democracia. Reflexiones desde el caso almeriense (Almería: 1977-1983)

- VV.AA. (1988): Las Españolas ante la política. Madrid: Instituto de la Mujer Instituto I.D.E.S.

- VV.AA. (1999): Españolas en la Transición. De excluidas a protagonistas. Madrid: Biblioteca Nueva.

- VV.AA. (1986): La mujer española: de la tradición a la modernidad (1960-1980). Seminarios de Estudios Sociológicos. Madrid: Ed. Tecnos.

\section{FUENTES}

\section{ARTículos DE REVISTAS:}

- Aróstegui, J. (1998): "Un nuevo horizonte de la historiografía contemporaneísta", en Cuadernos de Historia Contemporánea, no 20.

- Caillavet, F. (1987): "Trabajo u honor: el trabajo femenino en la economía contemporánea", en Reis, Revista Española de Investigaciones Sociológicas. № 40. pp. 113-134.

- Guzmán, V. (2001): "La institucionalidad de género en el Estado: nuevas perspectivas de análisis", en CEPAL, Unidad Mujer y Desarrollo, Serie Mujer y Desarrollo, n 32, marzo.

- Ruiz Franco, R. (1995), "Nuevos Horizontes para las mujeres de los años 60, la Ley de 22 de julio de 1961", Arenal, Vol. 2. n², pp. 247-268.

\section{Artículos en Volumen Colectivo:}

- García Nieto, M. C. (1993): Trabajo y oposición popular de las mujeres durante la dictadura franquista. En DUBY, Michelle: Historia de las Mujeres. Siglo XX, Vol. 5. Madrid: Taurus. p. 723.

- Lagrave, R. M. (1993): “Una emancipación bajo tutela: Educación y Trabajo de las Mujeres en el s. XX”, en DUBY, Michelle.: Historia de las Mujeres. Siglo XX, Vol. 5. Madrid: Taurus, pp. 524-525. 
- Vanaclocha, M. M. (1999): "Las Mujeres en el mundo laboral", en VV.AA.: Españolas en la Transición. De excluidas a protagonistas .Madrid: Biblioteca Nueva. p.274.

OTRAS FUENTES DE INTERÉS:

- II Congreso del Partido Socialista Obrero Español de Andalucía. Sevilla, 7-9 diciembre de 1979. Memoria de Ponencias sobre Mujer. Pp. 87-89. Archivo del Partido Socialista Obrero Español de Almería. Sección Elecciones 1979. Legajo 1. Almería.

- Diario La Voz de Almería (1977-1979).

- Boletín Oficial de la Provincia de Almería. 1977-1983. 